$\rightarrow$ Note: This document is superseded by DHHS (NIOSH) Publication No. 2004110, Preventing Lung Disease in Workers Who Use or Make Flavorings4 4

NIOSH Evaluates Worker Exposures at a Popcorn Plant in Missouri 


\section{NIOSH Evaluates Worker Exposures at a Popcorn Plant in Missouri}

\section{Fact Sheet}

July 2002

The Centers for Disease Control and Prevention's (CDC) National Institute for Occupational Safety and Health (NIOSH) is working with management, employees, State health officials, and others to assess workers' potential risk for a serious lung disease from occupational exposures at a company's popcorn packaging plant in Jasper, Missouri. NIOSH has made interim recommendations to reduce exposures as further study continues.

From 1992 to 2000, eight former workers of the Gilster-Mary Lee popcorn plant in Jasper, Missouri, developed a rare lung disease called bronchiolitis obliterans. The disease was severe enough for some workers to cause them to be placed on lung transplant lists. In August 2000, the Missouri Department of Health asked NIOSH to determine if these cases of lung disease were due to an exposure at the plant, and if any current workers were at risk. After preliminary surveys were completed, NIOSH recommended that all workers in microwave popcorn production at the plant wear respiratory protection.

In November 2000, NIOSH conducted voluntary tests of workers at the plant including confidential questionnaires, breathing tests, and chest x-rays. Current workers had chronic cough and shortness of breath 2.6 times as often as would be expected based on national surveys. Breathing tests showed abnormally low airflow 3.3 times as often as would be expected. About twice as many workers as would be expected had been told by their physicians that they had asthma or chronic bronchitis.
In November 2000, NIOSH also measured the air concentrations of dust and some of the ingredients of butter flavoring, including diacetyl, a common ingredient in artificial butter flavoring. Workers who spent more time in areas with higher air concentrations of these substances were more likely to have abnormal airflow in their breathing tests. Higher exposures over time were associated with lower airflow.

The testing results led NIOSH to make recommendations for improvements to the ventilation of the plant. The company made these changes, and repeated measurements showed that the amount of dust and flavoring ingredients in the air of the plant decreased significantly. NIOSH also reemphasized use of respirators by microwave popcorn production workers.

NIOSH repeated testing of current workers in April and August 2001. Some workers had excessive declines in their breathing tests despite the improvements in the ventilation of the plant. It is not clear if the abnormal declines in breathing tests are due to the earlier higher exposures to airborne 
dust and flavoring ingredients or if the lower air concentrations may still be too high. NIOSH recommended that the company completely isolate the sources of flavoring and dust in the air to prevent further exposure of workers. The company is presently implementing the necessary changes.

In tests at NIOSH, laboratory rats that breathed high concentrations of vapors from the flavoring developed significant airway damage in their lungs. A component of the flavoring, diacetyl, was used as a marker for exposure because it is easy to measure, but it is still unclear what role diacetyl may or may not play in the development of respiratory illness in workers exposed to the flavoring.

NIOSH, in cooperation with Gilster-Mary Lee, will continue to monitor workers' lung function until it is no longer decreasing faster than would be expected with normal aging. NIOSH will also continue tests of air levels to assess the effectiveness of engineering changes made by the plant.

NIOSH has worked extensively with employees, the community, the company, and health professionals to disseminate its findings and recommendations. In addition to immediate individual notification to workers of their test results, NIOSH held town meetings in Jasper, Missouri, in September 2001, in order to share its interim findings with workers and others in the community, emphasize the importance of respirator use by microwave production workers, and encourage continued participation in medical testing as the investigation continues. NIOSH also presented its interim findings and recommendations to local health care providers in September 2001.

The current data indicate that bronchiolitis obliterans occurring in former workers of this plant is most likely due to the workers' occupational exposure to inhaled flavoring vapors. Further research is needed to conclusively identify the cause and the circumstances under which the risk occurs. NIOSH is conducting surveys of other companies that use flavorings to see if other workers are at risk. These efforts will enable the development of guidelines for safe use of flavorings by all companies. The current investigation focuses on issues of worker safety. NIOSH is not aware of any evidence to suggest danger to consumers in the preparation and consumption of microwave popcorn.

For more information about NIOSH research, call the toll-free NIOSH information number at 1-800-35-NIOSH (1-800-356-4674) or visit $\mathrm{NIOSH}$ on the Web at www.cdc.gov/niosh.

SAFER • HEALTHIER • PEOPLETM

DHHS (NIOSH) Publication No. 2002-128

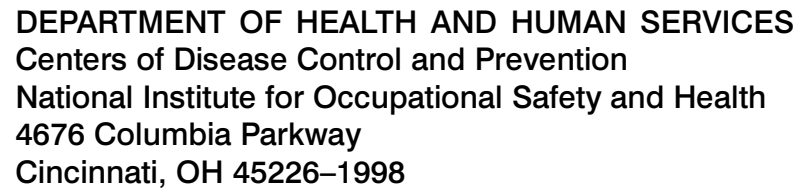

